\title{
EVIDENCE FOR PULMONARY VASOCONSTRICTION IN MAN
}

\author{
BY \\ RICHARD GORLIN*, FRANK B. CLARE, AND JOSEPH J. ZUSKA \\ From the U.S. Naval Hospital, Portsmouth, Virginia, U.S.A.
}

Received October 15, 1957

The occurrence of pulmonary vasomotor activity has been one of the most highly disputed subjects in modern medicine. Probably the most decisive studies of pulmonary vasomotion were those of Daly and his collaborators (1952). Over the course of the last fifteen years by elaborately devised experiments under rigidly controlled conditions, they demonstrated in animals the occurrence of both vasoconstriction and vasodilatation of the pulmonary vascular bed. They showed that vasoconstrictor fibres were unmasked following atropinization and that these fibres ran in the cervical vago-sympathetic chain.

Generalized hypoxia has been stated to cause mild vasoconstriction in normal man (Westcott et al., 1951; Doyle et al., 1952), although unilateral studies have not shown vasoconstriction in the hypoxic lung (Fishman et al., 1955). Similarly, mild vasoconstrictor effects have been attributed to epinephrine by Witham and Fleming (1951), but not to nor-epinephrine (Fowler et al., 1951). The findings in most of these studies have been minimal and some authorities have doubted whether there is major neural and humoral control of the lesser circulation in normal man (Hamilton et al., 1939; Cournand, 1947). On the other hand, an elevated pulmonary vascular resistance may be decreased by an autonomic blocking agent (Fowler et al., 1950); and in mitral stenosis, a rapid partial regression in raised resistance is often seen within the first two to four weeks following successful valvotomy (Dexter et al., 1950; Lukas and Dotter, 1952).

In the course of study of a patient with primary pulmonary hypertension, unexpected acute changes in pulmonary arterial pressure and blood flow were observed. It is the purpose of this report first to present these data and secondly to record the apparent inefficacy of bilateral stellate ganglion block in the treatment of primary pulmonary hypertension.

\section{CASE REPORT}

The patient was a 42-year-old, white, married mother of two, who was admitted to this hospital with the chief complaint of chest pain. Except for a single attack of unexplained syncope six years ago she had been in good health until approximately one year before admission, at which time she had a sudden and severe hæmoptysis of approximately one cupful of bright red blood. X-ray revealed diffuse haziness of the right upper lobe which cleared. Bronchoscopy was normal. This event recurred four months prior to admission. During the preceding year the patient noted the erratic occurrence of a poorly localized and poorly described heavy pain over the præcordial and substernal areas, not particularly related to effort and with no radiation. She also noticed mild shortness of breath on exertion but was still able to carry on with her housework until shortly before the admission. She did not experience syncope, frank right heart failure, or cyanosis. Physical examination on admission showed a well-developed, well-nourished woman with blood pressure 105/80, pulse 70, respiration 16 . There was no clubbing, cyanosis, nor jugular venous distension. The lungs expanded normally and were normal on percussion and auscultation. The heart showed no enlargement. There was a slight heaving sensation over the pulmonary outflow tract. The pulmonary second sound was much accentuated and louder than the aortic second sound. The first heart

\footnotetext{
* Present address: Peter Bent Brigham Hospital, Boston, Mass.
} 
sound was normal and there were no murmurs: a third sound was heard in early diastole along the left sternal border. The rest of the physical examination was within normal limits. Electrocardiogram initially showed no abnormalities except that the $\mathrm{R} / \mathrm{S}$ ratio equalled 0.8 in V1 (Fig. 1). The X-ray of the chest showed a normal heart with enlarged main pulmonary artery and major branches: there was marked diminution in size of the secondary and tertiary branches. An angiocardiogram revealed conspicuous dilatation of the pulmonary artery with arrest of the dye in the main trunk. The dye was then distributed through diminutive branches. During this admission the patient was subjected to cardiac catheterization. The pertinent findings are shown in Table I. To be noted are the normal arterial oxygen saturation, the high

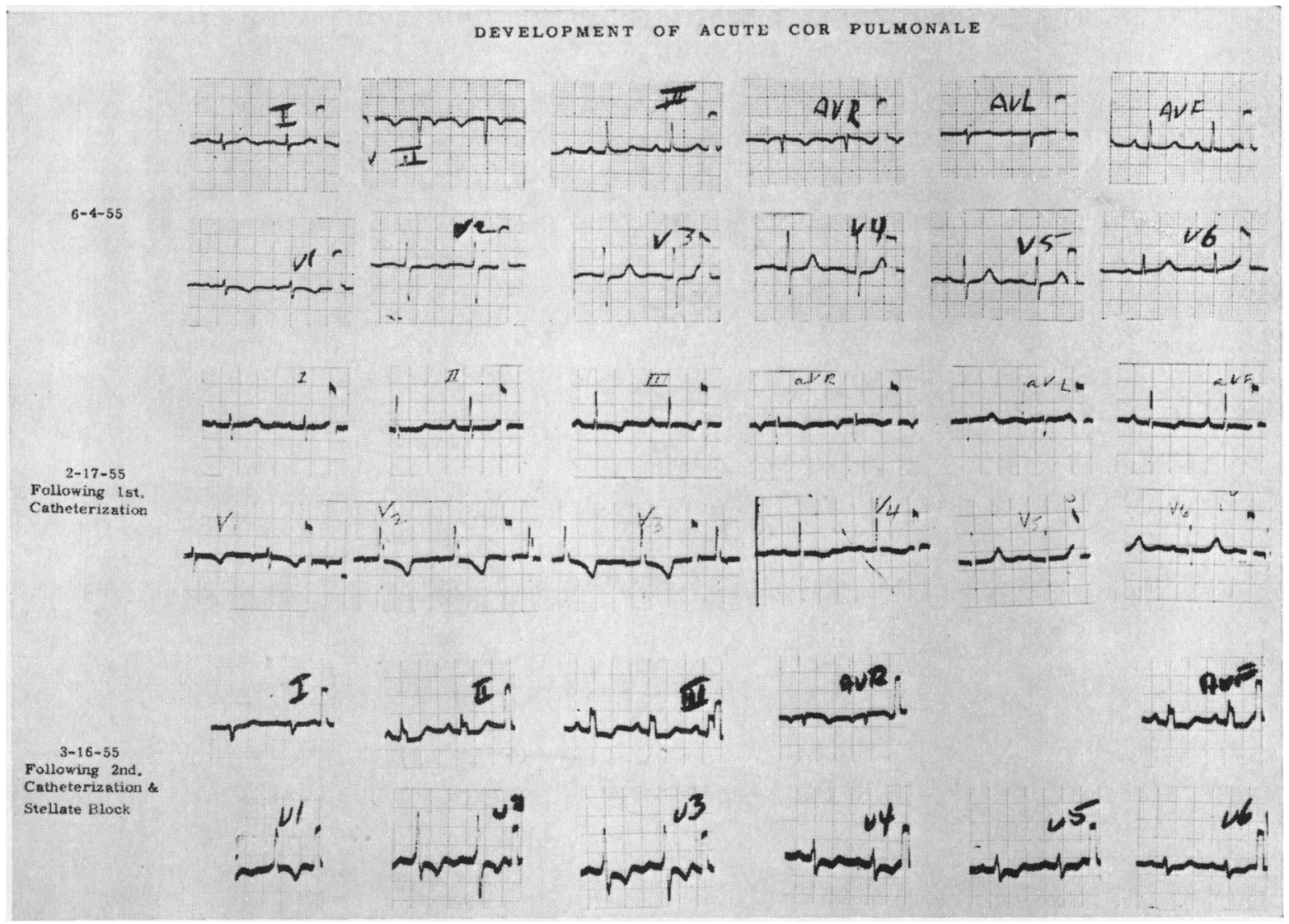

Fig. 1.-Development of acute cor pulmonale. The dates on the left should read 6/4/55, 17/2/56, 16/3/56.

TABLE I

Findings on Cardiac Catheterization during Treatment of Pulmonary Hypertension

\begin{tabular}{|c|c|c|c|c|}
\hline & Normal rest & $17 / 2 / 56$ rest & Ex. & $16 / 3 / 56$ rest \\
\hline $\begin{array}{l}\text { Arterial } \mathrm{O}_{2} \text { saturation, per cent } \\
\text { Cardiac output, } 1 / \mathrm{min} . / \mathrm{m} .^{2} . \\
\text { Pulmonary arterial mean pressure, mm. } \mathrm{Hg} \\
\text { Pulmonary wedge pressure, } \mathrm{mm} \text {. } \mathrm{Hg} . \\
\text { Systemic arterial pressure, } \mathrm{mm} \text {. } \mathrm{Hg} \\
\text { Right atrial mean pressure, } \mathrm{mm} \text {. } \mathrm{Hg} . \\
\text { Pulmonary vascular resistance, dynes. }\end{array}$ & $\begin{array}{c}96-99 \\
3-4 \\
12-15 \\
5-10 \\
95 \\
0-3 \\
100\end{array}$ & $\begin{array}{r}99 \\
1 \cdot 9 \\
60 \\
7 \\
95 \\
4 \\
1570\end{array}$ & $\begin{array}{c}100 \\
2 \cdot 4 \\
78 \\
5 \\
88 \\
8 \\
1690\end{array}$ & $\begin{array}{c}95 \\
2 \cdot 7 \\
75 \\
5 \\
105 \\
3 \\
1540\end{array}$ \\
\hline
\end{tabular}


pulmonary arterial pressure with normal pulmonary wedge pressure, the extremely low cardiac output, and the increased pulmonary vascular resistance. During exercise a small increase in output occurred; pulmonary vascular resistance did not change; but the right atrial mean pressure rose while the brachial arterial pressure decreased.

The patient was given priscoline, 100 milligrams orally four times a day for two weeks and intramuscularly for one week. At the end of this time there had been no change in her symptoms, electrocardiogram, or chest X-ray. Cardiac catheterization was repeated and revealed no change in pulmonary arterial pressure or resistance, indicating that priscoline had been ineffective. Because of encouraging reports concerning stellate ganglion block in the treatment of acute pulmonary embolism it was decided to observe the effects of this procedure during cardiac catheterization. A left stellate block was performed with 1 per cent procaine. Observations were made following production of a Horner's sign. Essentially no change occurred in pulmonary arterial pressure or vascular resistance (Fig. 2). Following these measurements a right stellate ganglion block was performed, again with no change in pulmonary hæmodynamics. Considerable needling of the right cervical region was necessary to maintain a block. At this point the patient began to complain of severe anterior chest pain, unaffected by respiration. She was thereupon given $0 \cdot 6 \mathrm{mg}$. of nitroglycerin which produced a mild fall in systemic and pulmonary arterial pressures. A Fick cardiac output measured at this time revealed a decrease of 1.2 litres a minute over the control with a calculated rise in both vascular resistances. The pain continued unabated. Observations four minutes

\section{CIRCULATORY STUDIES DURING ACUTE PULMONARY VASOCONSTRICTION}

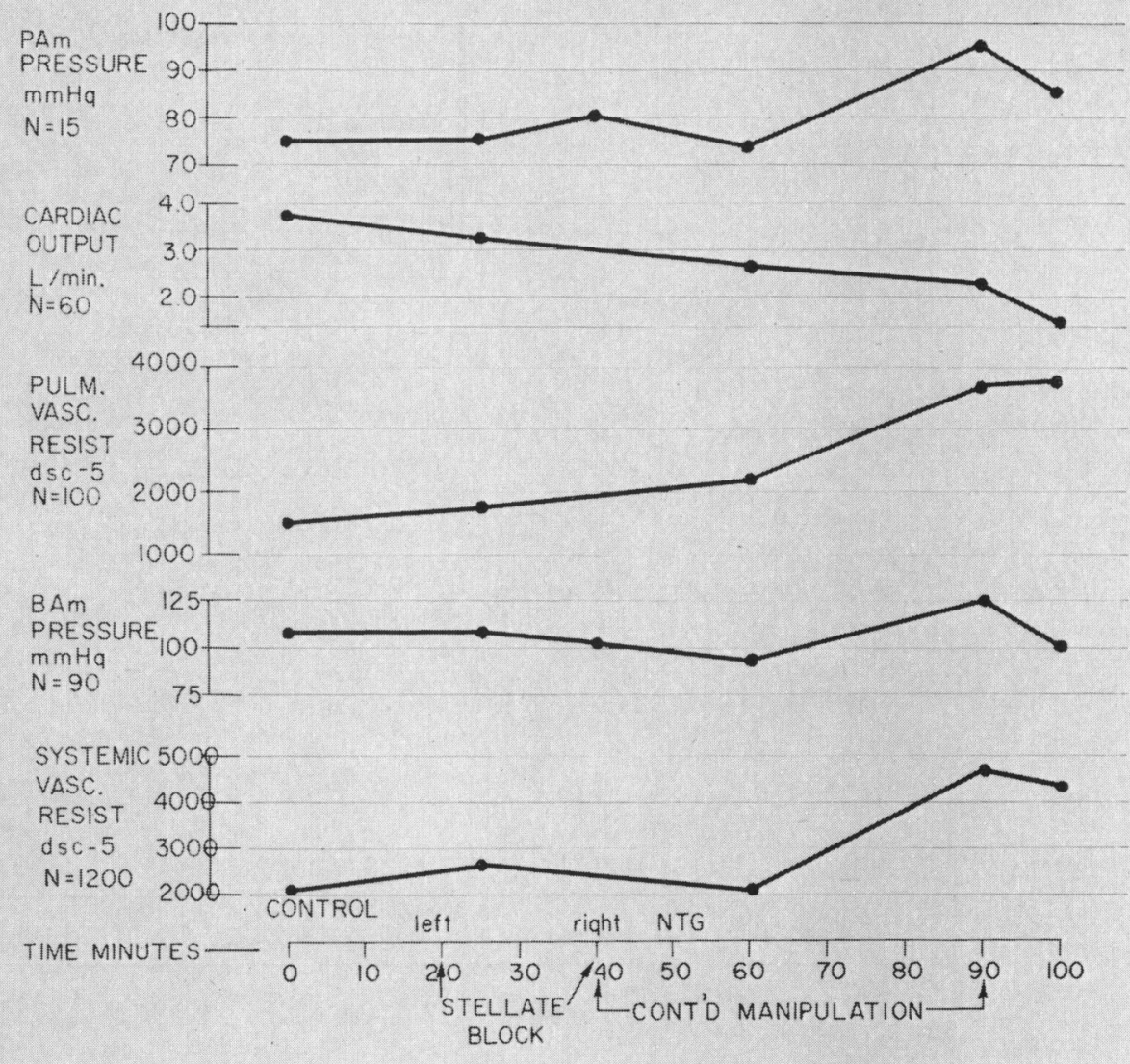

FIG. 2.-Circulatory studies during acute pulmonary vasoconstriction. 
following the nitroglycerin revealed a systemic blood pressure of $140 / 110$ with a mean of $125 \mathrm{~mm}$. $\mathrm{Hg}$, pulmonary arterial pressure of 95 , pulmonary wedge pressure of 8 , a cardiac output of $2 \cdot 1$ litres a minute, and a calculated resistance of 3600 dynes. sec. cm. ${ }^{-5}$. The patient was then given 100 milligrams of demerol, which only partially relieved the pain. Mean systemic blood pressure nevertheless remained at 82 while the cardiac output had further decreased to less than one-half of the control value. The calculated pulmonary vascular resistance had increased to twice the original measurement. Right atrial pressure at this time had risen from 3 to $10 \mathrm{~mm}$. $\mathrm{Hg}$. An electrocardiogram revealed the changes of acute cor pulmonale (Fig. 2). Physical examination and fluoroscopy showed no evidence of gross pneumothorax at this time.

Because of the patient's persistent pain, the failure of relief by stellate ganglion block, and the acute pulmonary hypertension, the procedure was abandoned and the patient returned to the ward where she gradually became more comfortable over the course of the afternoon. Approximately four hours following the procedure, however, she complained bitterly of recurrent chest pain. Physical examination revealed bilateral pneumothorax. $2700 \mathrm{ml}$. of air were removed from the left and $1000 \mathrm{ml}$. from the right pleural spaces with needle aspirations controlled by a pneumothorax apparatus and obtaining negative pressures in each pleural space. There was no improvement in the patient's clinical condition and one hour later, despite apparent re-expansion of the lungs, she died suddenly. Pertinent findings at necropsy were limited to the heart and lungs. The heart weighed 250 grams. The right ventricular wall measured 2 to 3 centimetres across. There was stenosis of the right coronary artery. Air escaped from each pleural space when the chest was opened under water. The lung parenchyma was collapsed but otherwise looked normal. The pulmonary vascular bed, however, revealed marked atherosclerosis with plaque formation throughout the larger medium and small branches. There were no gross thrombi or emboli. Microscopic examination revealed intimal thickening in the large pulmonary arteries. The smaller arterioles showed intimal thickening, medial hyalinization, and often fibrous obliteration of the lumen. In some of the small arterioles evidence of organizing thrombus was seen.

\section{COMMENT}

Because of the extremely unfavourable prognosis of primary pulmonary hypertension and the fact that this patient was severely although not yet critically ill with the disease, it was decided to try various forms of therapy. Dresdale et al. $(1951,1954)$ reported that priscoline was effective in lowering pulmonary arterial pressure when administered parenterally as a single dose. Our observations after two weeks' trial indicate this medication was ineffective over that period. Two independent groups of workers reported salutary clinical effects of stellate ganglion block on acute pulmonary embolism (Bageant and Rapee, 1947; Faxon et al., 1951): in some of the cases there was striking relief of pain, dyspnœa and anxiety. A search revealed no previous similar studies in chronic idiopathic pulmonary hypertension. Accordingly, bilateral stellate ganglion block was tried in our patient. A left stellate ganglion block had no effect on the pulmonary vasculature in this patient. While a completely successful right stellate block was not achieved, the actual aggravation of pulmonary hypertension during infiltration and manipulation of this ganglion would at least suggest that bilateral block is also without effect. The failure of this procedure to relieve pulmonary hypertension is similar to the inefficacy of pulmonary plexectomy and thoracic sympathectomy (Griswold; Simeone; personal communications). It is interesting that this latter procedure relieved severe symptoms in two patients although hæmodynamics remained unchanged.

The most striking observation in our patient was the development of pulmonary vasoconstriction within 30 minutes, with a rise in pulmonary arterial pressure and a fall in cardiac output. At the beginning of this response, systemic arterial pressure, systemic vascular resistance, and heart rate were all increased. The association of all these findings together would suggest that (i) a generalized sympathetic discharge had occurred related to pain or to stimulation of cervical autonomic ganglia; (ii) the pulmonary hypertension increased in response to acute left heart failure; and (iii) irritation or puncture of the apical pleura or production of a small radiologically undetectable pneumothorax with the injection needle initiated a nervous reflex resulting in acute pulmonary vascular constriction. The likelihood of sympathetic overactivity is supported by the experimental observations that cervical sympathetic stimulation in the dog results in pulmonary 
vasoconstriction (Daly and Hebb, 1952) and that the pulmonary constrictor response to hypoxia is blocked by sympathectomy (Stroud and Rahn, 1953). The second hypothesis is rendered unlikely by the fact that the pulmonary wedge pressure was not raised and that the systemic arterial hypertension receded during the next 30 minutes while the pulmonary vascular obstruction became more severe. No statement can be made concerning the third possibility. Associated with the acute increase in pulmonary obstruction was the development of acute cor pulmonale shown electrocardiographically (Fig. 1) and also hæmodynamically by a rise in right atrial mean pressure.

The authors believe that this is the first time that acute pulmonary constriction unrelated to pharmacological agents or hypoxia has been demonstrated in man under conditions where serial observations of pressures and flows could be made. The acute occurrence of this phenomenon would suggest that more attention be directed to the nervous and humoral factors which may initiate primary pulmonary hypertension. It was the authors' hope to correct the hypertension in this patient before it had progressed to the irreversible and critical stage. That this level was rapidly being approached was shown by the exercise response wherein the systemic blood pressure decreased and the right atrial pressure increased (Howarth and Lowe, 1953). In normal man arterial blood pressure rises and atrial pressure changes little with standard exercise. Findings at necropsy indicated that the disease was more severe than was judged clinically and that little change with autonomic blockade could have been expected.

This study again calls attention to one of the well-known hazards of bilateral stellate ganglion block, namely bilateral pneumothorax. It is believed that the chest pain in this patient was cardiac in origin and not necessarily related to the pneumothorax during the catheterization. Her final demise, however, was undoubtedly related to the sudden recurrence of bilateral tension pneumothorax. As has been pointed out by others (Howarth and Lowe, 1953; Schafer et al., 1956), relatively minor traumata, even after their apparent correction, have been sufficient to cause the death of patients with underlying primary pulmonary hypertension.

\section{SUMMARY}

A patient with primary pulmonary hypertension is reported, in whom acute pulmonary vasoconstriction apparently occurred during stellate ganglion block. Observations of pulmonary arterial pressure and flow and calculation of pulmonary vascular resistance were made from data obtained at cardiac catheterization during the procedure. This is believed to be evidence of the occurrence of an acute vascular constriction in the lungs of man.

\section{REFERENCES}

Bageant, W. E., and Rapee, L. A. (1947). Anesthesiology, 8, 500.

Cournand, A. (1947). Bull. N.Y. Acad. Med., 23, 27.

Daly, I. de B., Duke, H. N., Linzell, J. L., and Weatherall, J. (1952). Quart. J. Exp. Physiol., 37, 149.

and Hebb, C. (1952). Quart. J. Exp. Physiol., 37, 19. Dexter, L., Gorlin, R., Lewis, B. M., Haynes, F. W., and Harken, D. E. (1950). Trans Amer. clin. climat. Ass.,
62, 170 .

Doyle, J. T., Wilson, J. S., and Warren, J. V. (1952). Circulation, 5, 263.

Dresdale, D. T., Michton, R. T., and Schultz, M. (1954). Bull. N.Y. Acad. M., 30, 195.

-, Schultz, M., and Michton, R. T. (1951). Amer. J. Med., 11, 686.

Faxon, H. H., Flynn, J. H., and Anderson, R. M. (1951). New Engl. J. Med., 244, 586.

Fishman, A. P., Himmelstein, A., and Cournand, A. (1955). Federation Proc., 14, 48.

Fowler, N. O., Wescott, R. N., Hauenstein, V. D., Scott, R. C., and Mcguire, J. (1950). J. clin. Invest., 29, 1387.

,- , Scott, R. C., and McGuire, J. (1951). J. clin. Invest., 30, 517.

Griswold, H. A., personal communication.

Hamilton, W. F., Woodbury, R. A., and Vogt, E. (1939). Amer. J. Physiol., 125, 130.

Howarth, S., and Lowe, J. B. (1953). Brit. Heart J., 15, 47-54.

Lukas, D. S., and Dotter, C. T. (1952). Amer. J. Med., 12, 639.

Schafer, H., Blain, J. N., Ceballos, R., and Bing, R. J. (1956). Ann. intern. Med., 44, 505.

Simeone, F. A., personal communication.

Stroud, R. C., and Rahn, H. (1953). Amer. J. Physiol., 172, 211.

Westcott, R. N., Fowler, N. O., Scott, R. C., Hauenstein, V. D., and McGuire, J. (1951). J. clin. Invest., $30,957$.

Witham, A. C., and Fleming, J. W. (1951). I. clin. Invest., 30, 707. 